\title{
The transcription factor FOXL2 in ovarian function and dysfunction
}

\author{
Elfride De Baere1, Marc Fellous ${ }^{2,3,4}$ and Reiner A. Veitia ${ }^{5,6}$
}

${ }^{1}$ Center for Medical Genetics, Ghent University Hospital, Ghent, Belgium

${ }^{2}$ INSERM U567, Genetics and Development Department, Institut Cochin, Paris, France

${ }^{3}$ CNRS UMR8104, Institut Cochin, Paris, France

${ }^{4}$ Université Paris Descartes, Faculté de Médecine Cochin-Port-Royal, Paris, France

${ }^{5}$ UMR7592-CNRS, Institut Jacques Monod, Paris, France

${ }^{6}$ Université Denis Diderot, Paris VII, Paris, France

\begin{abstract}
The Blepharophimosis Ptosis Epicanthus-inversus Syndrome is a genetic disease characterized by complex eyelid malformations often associated with premature ovarian failure (POF). BPES is basically an autosomal dominant disease, due to mutations in the FOXL2 gene, which encodes a forkhead transcription factor. More than one hundred mutations of FOXL2 have been described to date. In agreement with the BPES phenotype, FOXL2 is expressed (though not exclusively) in the developing eyelids and in fetal and adult ovaries. Two mouse knock-out models have been produced. They recapitulate the BPES phenotype and have provided insights into the pathology. Loss-of-function mutations in FOXL2 are predicted to lead to BPES and POF, while hypomorphic mutations might lead to BPES without ovarian dysfunction. However, exceptions to the genotype-phenotype correlation have been described. To better understand the pathogenic effect of these mutations it is crucial to study the normal regulation of FOXL2 and its targets. We briefly address these aspects in this review and hope that basic research around FOXL2 will eventually lead to uncover new therapeutic avenues.
\end{abstract}

Key words: FOXL2, premature ovarian failure, blepharophimosis syndrome, menopause, oxidative stress

\section{Introduction}

The Blepharophimosis Ptosis Epicanthus-inversus Syndrome (BPES, MIM 110100) is a rare genetic disease mainly characterized by a complex eyelid malformation. Zlotogora et al. defined 2 forms of BPES: type I (with premature ovarian failure [POF]) and type II (without POF) [1]. BPES is most often an autosomal dominant disease due to mutations in the FOXL2 gene, which encodes a forkhead transcription factor [2]. In several mammals (human, mouse and goat) FOXL2 is detected in the developing eyelids and in fetal and adult ovaries. This pattern of expression correlates with the BPES phenotype $[2,3,4]$. Gonadal expression of FOXL2 in mammals starts at the moment of ovari-

Correspondence: Prof. Reiner A. Veitia, Université ParisDiderot/Paris 7 and Institut Universitaire de France. Mail to: Institut Jacques Monod, CNRS-UMR 7592, Bâtiment Buffon, Suite 555B, 15 Rue Hélene Brion, Paris Cedex 13, France. tel.: (+333) 157278116,

e-mail: veitia.reiner@ijm.univ-paris-diderot.fr an determination, and is maintained through adulthood. FOXL2 expression seems restricted to the somatic compartment of the ovary, with granulosa cells displaying the strongest protein expression $[2,4,5]$. Foxl2 is also expressed in the developing pituitary and might participate in its organogenesis $[6,7]$. This expression persists in the adult pituitary, especially in gonadotrope and thyrotrope cells [8]. An exploration of Internet resources suggests that FoxL2 is also expressed in macrophages, blood reticulocytes, hepatocytes, in the colon, in the heart, etc [9]. In addition, FOXL2 expression was demonstrated in human fibroblasts [10]. Such a wider expression domain of FOXL2 also suggests a role in the development and/or function of other tissues.

\section{Mouse models}

Two Knock-Out (KO) mouse models have been created for Foxl2 [11,12]. Homozygous KO animals display strong perinatal lethality [12]. The survivors are characterized by a small size, which is probably linked 
to a reduction of plasmatic Insulin-Like Growth Factor 1 (Igf1) level [12]. Moreover, they have severe craniofacial abnormalities, a severe eyelid hypoplasia, and are born with open eyes [12].

Female KO mice are sterile $[11,12]$. Their ovaries are small, disorganized and primary follicles are not formed [11,12]. Schmidt et al. (2004) observed a normal formation of primordial follicles whose granulosa cells fail to undergo the normal squamous-to-cuboidal morphological transition. Indeed, they stay 'flat' and do not proliferate [11]. In turn, Uda et al. (2004) described an earlier defect since their KO XX mice do not form correct primordial follicles [12]. Indeed, the main defect reported is a perturbation of fragmentation of the ovigerous cords [12]. These differences between the onset of the follicular formation defects might be due to differences in the genetic backgrounds of the two KO models or in the methods used for phenotypic analysis. Interestingly, germ cells do not seem affected during the first stages of folliculogenesis $[11,12]$. Perinatally, the number of oocytes is similar between mutant and wild-type mice but soon a massive follicular atresia leads to a severe depletion of the follicular stock and infertility $[11,12]$.

The Fox12-/- granulosa cells acquire Sertoli cellspecific characteristics, including expression of Sox9, $\mathrm{Amh}$, as well as other genes of the testicular differentiation program [13]. Interestingly, forced expression of Foxl2 in XY transgenic mice leads to seminiferous tubule disorganization and to the development of ovotestis-like gonads [14]. These observations suggest an 'anti-testis' action of Foxl2 by repressing the testis developmental program but also points to an important role in the ovary throughout female fertile life.

\section{FOXL2 mutations in BPES}

To date, more that 100 unique intragenic FOXL2 mutations (i.e. concerning the coding region) have been identified in 206 unrelated BPES families from different ethnic origin (15 and references therein). Detailed information on most FOXL2 mutations is available in the FOXL2 Mutation Database (http://medgen.ugent. be/fox12). Intragenic mutations explain about $72 \%$ of typical BPES cases $[15,16,17,18,19]$. Mutations leading to an expansion of the polyalanine/polyAla tract (p.Ala224_Ala234dup, 24 Ala residues instead of 14) account for $31 \%$ and the 17-bp duplication c.843 859dup (p.P287fs) accounts for $13 \%$ of all reported intragenic FOXL2 mutations. Another, less recurrent, 17-bp duplication c.855_871dup (p.H291fs), and mutations c.841 857dup (p.A364fs), c.843 865dup (p.H289fs), c.854delC (p.P285fs), and c.855 871del17 (p.P287fs), are all clustered in the same region, which suggests a hypermutability of this sequence $(15,17,19)$.
The expansion of the polyAla domain (Ala24) is most often found in type II BPES (i.e. no ovarian dysfunction) $[2,16]$. An Ala26 protein has been described in a BPES patient with an important ovarian cyst [20]. We have recently described a homozygous mutation leading to Ala19 in a consanguineous BPES family [21].

The phenotypic consequences of nonsense mutations depend on their position in the coding region (Fig. 1). Early truncation before the forkhead domain, is likely to lead to plain loss-of-function (and haploinsufficiency would be the cause of BPES, i.e. p.Q53X) [22,23] (Fig. 1A)). A nonsense mutation within the forkhead may also lead to the production of an inactive protein [16,24,25] (Fig. 1B). However, truncated FOXL2 proteins containing a complete forkhead domain, but lacking the polyAla, such as p.F167X, p.G196X or p.S203X $(16,25)$ might compete with the normal protein for DNA binding and lead to type I BPES $(16,17)$ (Fig. 1C). Protein truncations after the polyAla (i.e. removing the C-terminus) have also been reported (i.e. p.Y274X) [17,26] and may lead to both types of BPES [17] (Fig. 1D). Several artificial nonsense mutations have been shown to lead to the production of N-terminally truncated proteins by re-initiation of translation downstream of the premature stop codon. They seem to aggregate in the nucleus, and display partial mislocalisation to the cytoplasm. In addition, they retain a fraction of the wild-type protein [23].

The most recurrent mutation of FOXL2 p.Ala224_Ala234dup (FOXL2-Ala24) (Fig. 1D), leads to intranuclear aggregation and a mislocalization of the protein as a result of extensive cytoplasmic aggregation, whereas the normal FOXL2 protein exclusively localizes in the nucleus in a diffuse manner [27]. Moreover, p.Ala224_Ala234dup seems to somehow interfere with the availability/activity of a co-expressed normal FOXL2 [27]. Accordingly, a potential promoter-specific dominant-negative effect of FOXL2-Ala24 has been reported [28]. However, FOXL2-Ala24 seems to retain a partial transactivation capacity on high-affinity promoters, which might explain why it is most often associated with BPES without POF $[28,29]$.

The analysis of missense mutations responsible for BPES indicates that most of them map to the forkhead domain (Fig. 1E). Recently, we have studied the molecular consequences of 17 naturally-occurring FOXL2 missense mutations [30]. The subcellular localisation and aggregation pattern of the mutant FOXL2 proteins was variable and ranged from a wild-type pattern to extensive nuclear aggregation often concomitant with cytoplasmic mislocalisation and aggregation. We also studied the transactivation capacity of these mutants. Several mutations led to a loss-of-function, while 


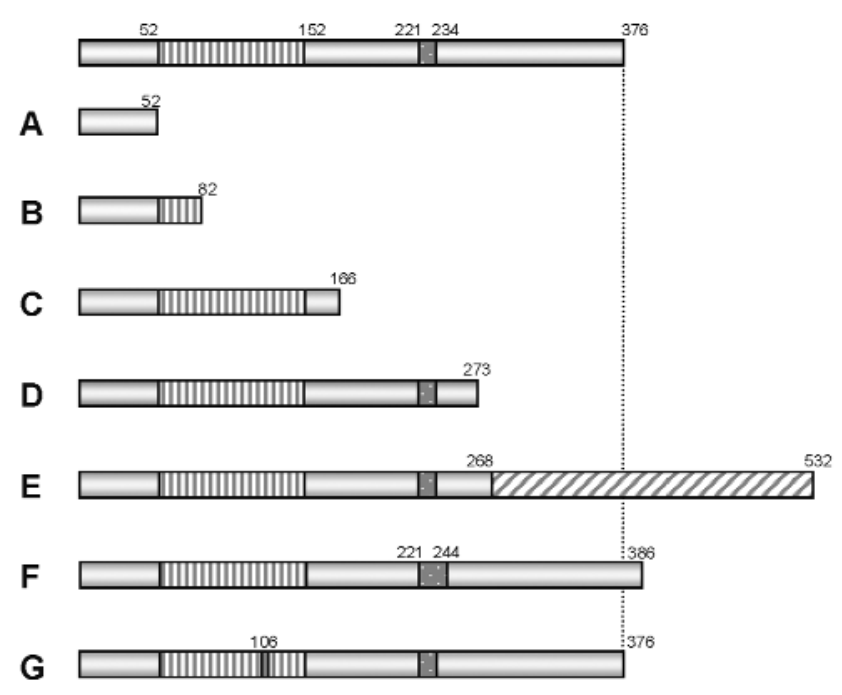

Fig. 1 The predicted protein translation of the wild type FOXL2 protein of 376 aminoacids (top). The vertically striped box indicates the forkhead domain, the dark grey small box shows the polyalanine (polyAla) tract and the diagonally striped boxes represent novel amino acids due to a frameshift mutation. The protein numbering is represented on top of the Figure. Different types of mutated proteins are shown. A-D are predicted truncated proteins: (A) without forkhead domain, (B) with partial forkhead, (C) with complete forkhead and without polyalanine (polyAla) tract, (D) with complete forkhead and polyAla domains. (E) represents frameshift mutations leading to elongated proteins with complete forkhead and polyAla domains; (F) polyAla expansions; $(\mathrm{G})$ missense mutation in the forkhead domain.

others were suspected to induce a weak dominant negative effect. Interestingly, two mutations, located outside the forkhead domain (p.S217F and p.S217C), gave rise to a mild BPES phenotype [30]. Using a structural 3D-model of the forkhead domain we have proposed that most of the mutations affecting the third helix of the forkhead domain, such as p.R103C, p.H104R or p.N105S alter DNA-binding while mutations in the first or second helices (i.e. p.I63T, p.A66V or p.E69L) might interfere with protein-protein interactions [26]. The variety of intragenic FOXL2 mutations suggests that its structure, localization and function are sensitive to seemingly mild alterations of the protein.

Frameshift mutations leading to elongated proteins induce the synthesis of (mostly) aberrant proteins. The position of mutation in the open reading frame (ORF) is expected to be crucial in the generation of a phenotype: the closer to the ATG, the more severe the potential phenotypic impact. Such abnormal proteins might have altered function and could also be toxic.

Genomic rearrangements, including deletions involving FOXL2, also cause BPES. They account for $10 \%$ of the molecular defects found in BPES families $[15,18]$. The extent of the deletions ranges from a partial or total gene deletion to microdeletions encompassing FOXL2 and neighbouring genes including ATR, located 5 ' to FOXL2. Other cytogenetic deletions found in

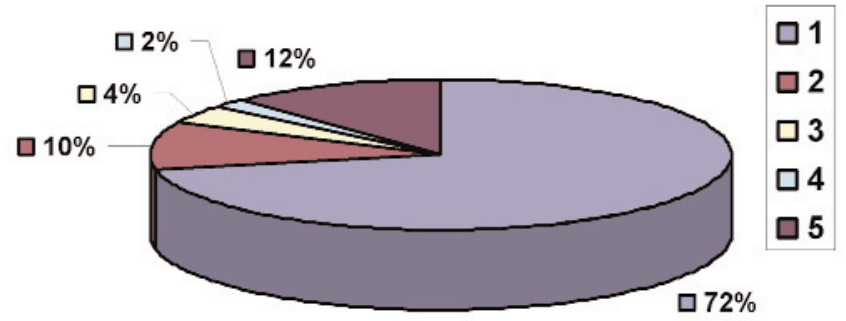

Fig. 2 Spectrum of genetic defects of the FOXL2 gene and region in our BPES cohort. (1) intragenic mutations $72 \%$; (2) FOXL2 deletions $10 \%$; (3) extragenic deletions $4 \%$; (4) cytogenetic defects $2 \%$; (5) unknown genetic defects $12 \%$.

BPES patients have been described [31 and references therein].

The occurrence of three translocation breakpoints located upstream of FOXL2 illustrated that position effects may also cause BPES. We have previously reported on nine extragenic deletions in BPES patients providing further evidence of potential long-range cisregulatory elements regulating FOXL2 expression $[10,18]$. The rearrangements outside the transcription unit are estimated to account for $5 \%$ of all molecular defects found in BPES $[15,18]$.

Before closing this section, it is worth noting that in a four-generation Chinese family with BPES type II showing linkage to the FOXL2 locus, an insertion mutation in the 3' UTR of FOXL2 segregated with the phenotype. However, the functional significance of this insertion (in an AU rich repeat) on transcript stability and/or translation needs to be studied [32].

\section{Genotype/phenotype correlations}

It seems difficult to predict the type of BPES just from the genotype. Type I is supposed to arise from null mutations, while type II BPES is expected to stem from hypomorphic (partial function) mutations in the ovary. An early mutation screening suggested that protein truncation was expected to lead to a type I BPES (i.e. with POF), whereas mutations leading to elongated proteins should produce a type II BPES (no ovarian dysfunction) [16]. However, predictions are almost impossible for missense mutations in the forkhead domain, as they lead to either type of BPES. Moreover, exceptions to the early genotype/phenotype correlations have been found, since the same mutation can lead to both types within the same family or in different families [15,17].

Overall, polyAla expansions lead to BPES type II. However, variable degrees of ovarian dysfunction have been observed in seven BPES patients with this mutation $[15,19]$. For those patients, it is hypothesized that these mutations may have a mild effect on ovarian function giving rise to late-onset ovarian failure, and 
permitting affected females to conceive at younger age [15]. Moreover, a 16-year old female BPES patient with an Ala26 expansion had an extremely large corpus luteum cyst, displayed ovarian dysfunction and was proposed to have BPES type I [20]. These cases emphasize the importance of appropriate clinical follow-up in patients carrying a polyAla expansion for a correct assessment of ovarian function. More generally they illustrate that predictive molecular testing for POF is only meaningful if complemented with clinical observations [15].

For mutations leading to a truncated or extended protein containing an intact forkhead and polyAla tract, the genotype cannot be consistently correlated to either type of BPES $[15,17]$.

In general, for FOXL2 missense mutations in the forkhead, no genotype-phenotype correlations can be made with respect to the ovarian phenotype. However, it is expected that missense mutations in the forkhead leading to mislocalization and aggregation, and thus severely impairing transactivation, will lead to a more severe ovarian phenotype than missense mutations not significantly affecting protein localization and function [19]. In addition, two mutations downstream of the forkhead domain (p.S217F and p.S217C), were found to lead to a mild BPES phenotype [30].

Although intragenic FOXL2 mutations usually lead to BPES type I or II without any extra associated symptoms, in some patients additional atypical features have been described, that might result from potential pleiotropic effects of these mutations (with very low penetrance) or due to other genetic or environmental factors. A ventricular septal heart defect (VSD) was found in a patient with a polyAla expansion (c.672_701dup; p.A224_A234dup) and one with a missense mutation in the forkhead domain (c.205G $>$ A; p.E69K) respectively. A developmental delay has been reported in patients carrying the mutation c. 273C $>\mathrm{G} \quad$ (p.Y91X), c.663 692dup (p.A221 A231) and c.1056delG (p.E352fs). The combination of a complex heart defect and severe developmental delay was described in a sporadic patient with mutation c.665C $>$ T (p.Q219X) [19]. An association between BPES and Duane syndrome was found in a 1-year old patient with an expansion of the poly-Ala tract (c.672 701dup; p.A224 A234dup) [33]. In another family in which mutation c.663 692dup (p.Ala221 Ala231dup) was found, a 7-year old male BPES patient was diagnosed with a cleft palate (Pierre Robin sequence) while his mother only displays typical BPES. Another patient with the mutation c.305T $>C$ (p.Ile102Thr) was born with a cleft lip [19].

Growth hormone deficiency, which has previously been described in two BPES patients without any other associated symptoms [34,35], was also found in one patient with the 17-bp duplication c.672 701dup
(p.A224 A234dup) [2], and two sisters with the missense mutation c.650C $>\mathrm{T}$ (p.S217F). In one BPES patient with mutation (c.500T $>A$; c. $501 \mathrm{C}>\mathrm{A}$ ) (2), growth retardation was observed. Growth hormone deficiency may be attributed to pituitary FOXL2 expression $[6,8]$. However, most BPES patients do not have a recognizable pituitary phenotype, suggesting that the pituitary is less sensitive than the developing eyelids and ovary to FOXL2 dosage.

For the deletions encompassing FOXL2, no reliable genotype-phenotype correlations could be established with respect to POF, as the type of BPES could not be determined in 9 out of 11 patients [18]. In the 2 families where assessment of ovarian function was possible, the FOXL2 deletion was found to lead to BPES type I. Furthermore, it was not possible to find a correlation between deletion size and developmental delay [18]. Although it was postulated that mental retardation in patients with a microdeletion of the FOXL2 region might be attributed to haploinsufficiency of ATR [31], a consistent correlation could not be found [18]. For deletions located outside FOXL2, the BPES type could only be assessed in 2 out of 5 families. They apparently displayed BPES type II [18]. Moreover, no developmental delay was observed in this subset of patients.

\section{Allelic disorders}

Considering that POF is part of the phenotypic spectrum of FOXL2 mutations, FOXL2 was assumed to be a possible candidate gene for non-syndromic POF $[2,36]$. However, the results of several studies demonstrate that mutations in the FOXL2 coding region are rarely associated with isolated POF $[16,37,38]$. However, FOXL2 variants were identified in two women with POF from New Zealand and Slovenia (absent in control chromosomes) [39]. A novel 30-bp deletion that was predicted to remove ten of 14 alanines from the polyAla tract (c.661 690del; g.898 927del; p.A221 A230del) was identified in a Slovenian woman who had spontaneously conceived and delivered two healthy children despite primary amenorrhea and hypergonadotrophic hypogonadism [40]. A novel single nucleotide substitution c.772T A (c.772T $>$ A; g.1009T A; p.Y258N) was identified in a New Zealand woman with POF and her unaffected mother. More recently, the mutation p.G187D was found in a woman with premature ovarian failure (POF) in absence of blepharophimosis syndrome (BPES). While FOXL2 localization was normal, the transactivation capacity of the mutant protein on two reporter promoters potentially relevant in an ovarian context promoters proved to be lower than that of normal FOXL2 [41]. 


\section{Regulation of FOXL2}

In order to better understand the pathogenic effect of FOXL2 mutations it is important to understand the normal regulation of the gene and the targets this transcription factor recognizes. FOXL2 is able to up-regulate the activity of its own promoter [29] which might explain why, once activated, FoxL2 expression is maintained throughout life [4]. FOXL2 has a rich pattern of post-translational modifications (PTM) isoforms in human granulosa-like KGN cells and in murine ovaries [42]. Perturbations of FOXL2 PTM profile through forced dephosphorylation or acetylation have revealed that FOXL2 contains multiple potential acetylations and phosphorylations [42]. This study has also suggested that the FOXL2 protein undergoes parallel processive/concerted modifications, leading to the existence of several 'mature' forms.

FOXL2 expression is upregulated under oxidative and heat stress in KGN cells [43]. Moreover, FOXL2 is also hyperacetylated in response to oxidative stress. The positive feedback of FOXL2 can be counteracted by a negative feedback through the NAD-dependent deacetylase SIRT1 [43]. Moreover, in vitro experiments indicate that the balance between the positive and negative feedback loops are disturbed by pathogenic mutations [43]. Beyond this coarse picture, further in-depth studies are required to better understand the subtleties of the regulation of FOXL2.

\section{Targets of FOXL2}

Two pituitary Foxl2 targets have been described thus far, the gonadotropin-releasing hormone receptor (GnRHR) and the glycoprotein hormone $\alpha$-subunit $(\alpha-G S U)[8,44]$. The expression of GnRHR is regulated through a composite regulatory sequence, the GnRHR activating sequence (GRAS). GRAS contains partially overlapping binding sites for Smad3, AP-1 and Foxl2 [44]. Thus, Foxl2 seems to play a role in the regulation of gonadotropin secretion. This is further supported by the fact that FOXL2 is able to stimulation $\alpha$-GSU expression in both a cellular model and in transgenic mice [8].

The analysis of Wnt4-/Foxl2-/ $\mathrm{KO}$ mice has shown that Amh is downregulated in the ovotestis-like gonads of Foxl2 transgenic XY mice [14]. These observations suggest that FOXL2 represses directly or indirectly the expression of SOX9 and AMH in XX gonads, avoiding ectopic activation of the male sexual differentiation pathway in females. FoxL2 is also known to regulate aromatase expression in numerous vertebrate species, such as goat, chicken and fishes $[3,45,46,47]$.

The Steroidogenesis Acute Response (StAR) catalyzes the translocation of the cholesterol from the outer to the inner mitochondrial membrane, where it undergoes transformation into pregnenolone and other steroids. FOXL2 has been shown to repress the transcriptional activity of the StAR promoter. StAR inhibition by FOXL2 is proposed to maintain immature follicles in a quiescent state [48]. The role of FOXL2 in steroid metabolism has been further shown in a recent transcriptome study comparing granulosa-like KGN cells overexpressing or not FOXL2 [49]. FOXL2 was found to upregulate the expression of other actors of steroid metabolism, such as PPARGC1A, NR5A2 and CH25H [49]. Other cellular pathways are perturbed by FOXL2 overexpression in KGN tumor cells. This is the case of several inflammatory chemokine ligands of the CCL and CXCL families, as well as of the Prostaglandin synthase 2 (PTGS2) [49]. These results are compatible with the idea that ovulation is an inflammatory-like process [50]. Massive follicular atresia occurring in Foxl2-/ovaries suggested that FoxL2 acted as an anti-apoptotic agent $[11,12]$. More recently, FOXL2 was proposed to be pro-apopototic [51]. This rather ambivalent behavior was illustrated by its ability to upregulate the expression of several (pro and anti) apoptosis regulators in KGN cells [49]. This ambivalence is shared by other forkhead factors and might be cell- or condition-dependent $[52,53]$.

FOXL2 overexpression in KGN cells induces the transcriptional activation of genes involved in the metabolism of reactive oxygen species (ROS) such as the Manganese mitochondrial Superoxide Dismutase $(\mathrm{MnSOD})$ [49]. A direct involvement of FOXL2 in cell stress response has been recently confirmed [43]. FOXL2 is upregulated by oxidative stress. At the protein level it is hyperacetylated, which correlates with an increased recruitment to stress-response promoters, as assessed by Chromatin Immunoprecipitation, and an increased transactivation capacity [43]. The gene encoding the SIRT1 deacetylase is also a direct target of FOXL2 [43]. Interestingly, deacetylation of FOXL2 by SIRT1 enhances the ability of the former to regulate the SIRT1 promoter [43]. This negative feedback loop could serve as a molecular brake, probably helping to return to "normal"" FOXL2 activity after the end of a stress. The issue of the regulation of the oxidative stress in the ovary is crucial because ovulation is accompanied by ROS generation [54].

The increasing number of known FOXL2 targets in the adult ovary [49] will be essential to reveal more insights into phenotypic effects of FOXL2 mutations in the adult ovary. Moreover, understanding the pathogenic mechanisms of its mutations might eventually lead to better diagnostic tools, helping differentiate the two BPES types, and to better therapies. We hope that basic research around the regulation of FOXL2 and its targets will eventually lead to uncover therapeutic molecules. 


\section{References}

[1] Zlotogora J, Sagi M, Cohen T. The blepharophimosis, ptosis, and epicanthus inversus syndrome: delineation of two types. Am J Hum Genet. 1983; 35(5):1020-1027.

[2] Crisponi L, Deiana M, Loi A, Chiappe F, Uda M, Amati P, Bisceglia L, Zelante L, Nagaraja R, Porcu S and others. The putative forkhead transcription factor FOXL2 is mutated in blepharophimosis/ptosis/epicanthus inversus syndrome. Nat Genet. 2001; 27(2):159-166.

[3] Pailhoux E, Vigier B, Vaiman D, Servel N, Chaffaux S, Cribiu $\mathrm{EP}$, Cotinot C. Ontogenesis of female-to-male sex-reversal in XX polled goats. Dev Dyn. 2002;224(1):39-50.

[4] Cocquet J, Pailhoux E, Jaubert F, Servel N, Xia X, Pannetier M, De Baere E, Messiaen L, Cotinot C, Fellous M and others. Evolution and expression of FOXL2. J Med Genet. 2002; 39(12):916-921.

[5] Pannetier M, Servel N, Cocquet J, Besnard N, Cotinot C, Pailhoux E. Expression studies of the PIS-regulated genes suggest different mechanisms of sex determination within mammals. Cytogenet Genome Res. 2003;101(3-4):199-205.

[6] Treier M, Gleiberman AS, O'Connell SM, Szeto DP, McMahon JA, McMahon AP, Rosenfeld MG. Multistep signaling requirements for pituitary organogenesis in vivo. Genes Dev. 1998; 12(11):1691-1704.

[7] Kioussi C, Carriere C, Rosenfeld MG. A model for the development of the hypothalamic-pituitary axis: transcribing the hypophysis. Mech Dev. 1999;81(1-2):23-35.

[8] Ellsworth BS, Egashira N, Haller JL, Butts DL, Cocquet J, Clay CM, Osamura RY, Camper SA. FOXL2 in the pituitary: molecular, genetic, and developmental analysis. Mol Endocrinol. 2006; 20(11):2796-2805.

[9] Moumné L, Batista F, Benayoun BA, Nallathambi J, Fellous M, Sundaresan P, Veitia RA. The mutations and potential targets of the forkhead transcription factor FOXL2. Mol Cell Endocrinol. 2008;282(1-2):2-11.

[10] D'haene B, Attanasio C, Beysen D, Dostie J, Lemire E, Bouchard $\mathrm{Ph}$, Field $\mathrm{M}$, Jones $\mathrm{K}$, Lorenz $\mathrm{B}$, Menten $\mathrm{B}$, Buysse K, Pattyn F, Friedli M, Ucla C, Rossier C, Wyss C, Speleman F, De Paepe A, Dekker J, Antonarakis SE, De Baere E. A distant deletion of a $7.4 \mathrm{~kb}$ fragment that harbours cis-regulators and that interacts with the FOXL2 promoter causes BPES. PLoS Genetics. 5(6):e1000522. Epub 2009 Jun 19.

[11] Schmidt D, Ovitt CE, Anlag K, Fehsenfeld S, Gredsted L, Treier AC, Treier M. The murine winged-helix transcription factor Fox12 is required for granulosa cell differentiation and ovary maintenance. Development. 2004; 131(4):933-942.

[12] Uda M, Ottolenghi C, Crisponi L, Garcia JE, Deiana M, Kimber W, Forabosco A, Cao A, Schlessinger D, Pilia G. Foxl2 disruption causes mouse ovarian failure by pervasive blockage of follicle development. Hum Mol Genet. 2004; 13(11):1171-1181.

[13] Ottolenghi C, Omari S, Garcia-Ortiz JE, Uda M, Crisponi L, Forabosco A, Pilia G, Schlessinger D. Fox12 is required for commitment to ovary differentiation. Hum Mol Genet. 2005; 14(14):2053-2062.

[14] Ottolenghi C, Pelosi E, Tran J, Colombino M, Douglass E, Nedorezov T, Cao A, Forabosco A, Schlessinger D. Loss of Wnt4 and Fox12 leads to female-to-male sex reversal extending to germ cells. Hum Mol Genet. 2007;16(23):2795-2804.

[15] Beysen D, De Paepe A, De Baere E. FOXL2 mutations and genomic rearrangements in BPES. Hum Mutat. 2009;30(2):158-169.

[16] De Baere E, Dixon MJ, Small KW, Jabs EW, Leroy BP, Devriendt K, Gillerot Y, Mortier G, Meire F, Van Maldergem $\mathrm{L}$ and others. Spectrum of FOXL2 gene mutations in blepharophimosis-ptosis-epicanthus inversus (BPES) families demonstrates a genotype--phenotype correlation. Hum Mol Genet. 2001;10(15):1591-1600.

[17] De Baere E, Beysen D, Oley C, Lorenz B, Cocquet J, De Sutter P, Devriendt K, Dixon M, Fellous M, Fryns JP and others. FOXL2 and BPES: mutational hotspots, phenotypic variability, and revision of the genotype-phenotype correlation. $\mathrm{Am} \mathrm{J}$ Hum Genet. 2003;72(2):478-487.

[18] Beysen D, Raes J, Leroy BP, Lucassen A, Yates JR, ClaytonSmith J, Ilyina H, Brooks SS, Christin-Maitre S, Fellous M and others. Deletions involving long-range conserved nongenic sequences upstream and downstream of FOXL2 as a novel disease-causing mechanism in blepharophimosis syndrome. Am J Hum Genet. 2005;77(2):205-218.

[19] Beysen D, De Jaegere S, Mowat D, Laframboise R, Gillessen-Kaesbach G, Fellous M, Veitia RA, Boucard P, Touraine P, Leroy BP and others. Mutation in Brief: Identification of 34 novel and 56 known FOXL2 mutations in patients with Blepharophimosis syndrome. Human Mutation. 2008;29(11):E205-19.

[20] Raile K, Stobbe H, Trobs RB, Kiess W, Pfaffle R. A new heterozygous mutation of the FOXL2 gene is associated with a large ovarian cyst and ovarian dysfunction in an adolescent girl with blepharophimosis/ptosis/epicanthus inversus syndrome. Eur J Endocrinol. 2005;153(3):353-358.

[21] Nallathambi J, Moumne L, De Baere E, Beysen D, Usha K, Sundaresan P, Veitia RA. A novel polyalanine expansion in FOXL2: the first evidence for a recessive form of the blepharophimosis syndrome (BPES) associated with ovarian dysfunction. Hum Genet. 2007;121(1):107-112.

[22] Ramirez-Castro JL, Pineda-Trujillo N, Valencia AV, Muneton CM, Botero O, Trujillo O, Vasquez G, Mora BE, Durango N, Bedoya $\mathrm{G}$ and others. Mutations in FOXL2 underlying BPES (types 1 and 2) in Colombian families. Am J Med Genet. 2002;113(1):47-51.

[23] Moumne L, Fellous M, Veitia RA. Deletions in the polyAlanine-containing transcription factor FOXL2 lead to intranuclear aggregation. Hum Mol Genet. 2005; 14(23):3557-3564.

[24] Dollfus H, Stoetzel C, Riehm S, Lahlou Boukoffa W, Bediard Boulaneb F, Quillet R, Abu-Eid M, Speeg-Schatz C, Francfort JJ, Flament J and others. Sporadic and familial blepharophimosis -ptosis-epicanthus inversus syndrome: FOXL2 mutation screen and MRI study of the superior levator eyelid muscle. Clin Genet. 2003; 63(2):117-120.

[25] Udar N, Yellore V, Chalukya M, Yelchits S, Silva-Garcia R, Small K. Comparative analysis of the FOXL2 gene and characterization of mutations in BPES patients. Hum Mutat. 2003;22(3):222-228.

[26] Nallathambi J, Laissue P, Batista F, Benayoun BA, Lesaffre C, Moumné L, Pandaranayaka PE, Usha K, Krishnaswamy S, Sundaresan P, Veitia RA. Differential functional effects of novel mutations of the transcription factor FOXL2 in BPES patients. Hum Mutat. 2008;29(8):E123-E131.

[27] Caburet S, Demarez A, Moumne L, Fellous M, De Baere E, Veitia RA. A recurrent polyalanine expansion in the transcription factor FOXL2 induces extensive nuclear and cytoplasmic protein aggregation. J Med Genet. 2004;41(12):932-936.

[28] Benayoun BA, Caburet S, Dipietromaria A, Bailly-Bechet M, Batista F, Fellous M, Vaiman D, Veitia RA. The identification and characterization of a FOXL2 response element provides insights into the pathogenesis of mutant alleles. Hum Mol Genet. 2008;17(20):3118-3127.

[29] Moumné L, Dipietromaria A, Batista F, Kocer A, Fellous M, Pailhoux E, Veitia RA. Differential aggregation and functional impairment induced by polyalanine expansions in FOXL2, a transcription factor involved in cranio-facial and ovarian development. Hum Mol Genet. 2008;17(7):1010-1019.

[30] Beysen D, Moumné L, Veitia RA, Peters H, Leroy BP, De Paepe A, De Baere E. Missense mutations in the forkhead 
domain of FOXL2 lead to subcellular mislocalisation, protein aggregation and impaired transactivation. Human Molecular Genetics. 2008b;17(13):2030-2038.

[31] de Ru MH, Gille JJ, Nieuwint AW, Bijlsma JB, van der Blij JF, van Hagen JM. Interstitial deletion in $3 q$ in a patient with blepharophimosis-ptosis-epicanthus inversus syndrome (BPES) and microcephaly, mild mental retardation an growth delay: clinical report and review of the literature. $\mathrm{Am} \mathrm{J} \mathrm{Med}$ Genet. 2005;15(137(1)):81-87.

[32] Qian X, Shu A, Qin W, Xing Q, Gao J, Yang J, Feng G, He L. A novel insertion mutation in the FOXL2 gene is detected in a big Chinese family with blepharophimosis-ptosis-epicanthus inversus. Mutat Res. 2004;554(1-2):19-22.

[33] Vincent AL, Watkins WJ, Sloan BH, Shelling AN. Blepharophimosis and bilateral Duane syndrome associated with a FOXL2 mutation. Clin Genet. 2005; 68(6):520-523.

[34] Varghese B, Donnai D, Shalet SM. Isolated growth hormone deficiency and BPES. Endocrine abstracts. 2002;3:P13.

[35] Wales JKH. Hypergonadotropic hypogonadism in a 3-yearold girl with blepharophimosis, ptosis, and epicanthus inversus syndrome. Hormone Research. 1998;50(6):341-341.

[36] Prueitt and Zinn. A fork in the road to fertility. Nat Genet. 2001;27(2):132-134

[37] De Baere E, Lemercier B, Christin-Maitre S, Durval D, Messiaen L, Fellous M, Veitia R. FOXL2 mutation screening in a large panel of POF patients and XX males. J Med Genet. 2002;39(8):e43.

[38] Bodega B, Porta C, Crosignani PG, Ginelli E, Marozzi A. Mutations in the coding region of the FOXL2 gene are not a major cause of idiopathic premature ovarian failure. Mol Hum Reprod. 2004;10(8):555-557.

[39] Harris SE, Chand AL, Winship IM, Gersak K, Aittomaki K, Shelling AN. Identification of novel mutations in FOXL2 associated with premature ovarian failure. Mol Hum Reprod. 2002;8(8):729-733.

[40] Gersak K, Harris SE, Smale WJ, Shelling AN. A novel 30 bp deletion in the FOXL2 gene in a phenotypically normal woman with primary amenorrhoea: Case report. Hum Reprod. 2004; 19(12):2767-2770.

[41] Laissue P, Besma Lakhal B, Benayoun B, Dipietromaria A, Braham R, Elghezal H, Philibert P, Saâd A, Sultan C, Fellous $\mathrm{M}$, and Veitia RAV. Functional evidence implicating FOXL2 in non syndromic premature ovarian failure and in the regulation of the transcription factor OSR2. J Med Gen. In press.

[42] Benayoun BA, Auer J, Caburet S, Veitia RA. The post-translational modification profile of the forkhead transcription factor FOXL2 suggests the existence of parallel processive/concerted modification pathways. Proteomics. 2008;8(15):3118-3123.

[43] Benayoun BA, Batista F, Auer J, Dipietromaria A, L'Hôte D, De Baere E, Veitia RA. Positive and negative feedback regu- lates the transcription factor FOXL2 in response to cell stress: evidence for a regulatory imbalance induced by disease-causing mutations. Hum Mol Genet. 2009;18(4):632-644.

[44] Ellsworth BS, Burns AT, Escudero KW, Duval DL, Nelson SE, Clay CM. The gonadotropin releasing hormone $(\mathrm{GnRH})$ receptor activating sequence (GRAS) is a composite regulatory element that interacts with multiple classes of transcription factors including Smads, AP-1 and a forkhead DNA binding protein. Mol Cell Endocrinol. 2003;206(1-2):93-111.

[45] Govoroun MS, Pannetier M, Pailhoux E, Cocquet J, Brillard JP, Couty I, Batellier F, Cotinot C. Isolation of chicken homolog of the FOXL2 gene and comparison of its expression patterns with those of aromatase during ovarian development. Dev Dyn. 2004; 231(4):859-870.

[46] Baron D, Cocquet J, Xia X, Fellous M, Guiguen Y, Veitia RA. An evolutionary and functional analysis of FoxL2 in rainbow trout gonad differentiation. J Mol Endocrinol. 2004; 33(3):705-715.

[47] Nakamoto M, Matsuda M, Wang DS, Nagahama Y, Shibata N. Molecular cloning and analysis of gonadal expression of Fox12 in the medaka, Oryzias latipes. Biochem Biophys Res Comm. 2006;344(1):353-361.

[48] Pisarska MD, Bae J, Klein C, Hsueh AJ. Forkhead L2 Is Expressed in the Ovary and Represses the Promoter Activity of the Steroidogenic Acute Regulatory Gene. Endocrinology. 2004;145(7):3424-3433.

[49] Batista F, Vaiman D, Dausset J, Fellous M, Veitia R. Potential targets of FOXL2, a transcription factor involved in craniofacial and follicular development, identified by transcriptomics. Proc Natl Acad Sci. 2007;104(9):3330-3335.

[50] Espey LL, Norris C, Forman J, Siler-Khodr T. Effect of indomethacin, cycloheximide, and aminoglutethimide on ovarian steroid and prostanoid levels during ovulation in the gonadotropin-primed immature rat. Prostaglandins. 1989;38(5):531-539.

[51] Lee K, Pisarska MD, Ko JJ, Kang Y, Yoon S, Ryou SM, Cha KY, Bae J. Transcriptional factor FOXL2 interacts with DP103 and induces apoptosis. Biochem Biophys Res Commun. 2005;336(3):876-881.

[52] Brunet A, Bonni A, Zigmond MJ, Lin MZ, Juo P, Hu LS, Anderson MJ, Arden KC, Blenis J, Greenberg ME. Akt promotes cell survival by phosphorylating and inhibiting a Forkhead transcription factor. Cell. 1999;96(6):857-868.

[53] Burgering BM, Medema RH. Decisions on life and death: FOXO Forkhead transcription factors are in command when PKB/Akt is off duty. J Leukoc Biol. 2003;73(6):689-701.

[54] Agarwal A, Gupta S, Sharma R. Oxidative stress and its implications in female infertility - a clinician's perspective. Reprod Biomed Online. 2005;11(5):641-650. 